\title{
Biodegradation of used engine oil by novel strains of Ochrobactrum anthropi HM-1 and Citrobacter freundii HM-2 isolated from oil-contaminated soil
}

\author{
Haytham M. M. Ibrahim ${ }^{1}$
}

Received: 5 June 2016/Accepted: 3 October 2016/Published online: 19 October 2016

(c) The Author(s) 2016. This article is published with open access at Springerlink.com

\begin{abstract}
Used engine oil (UEO) constitutes a serious environmental problem due to the difficulty of disposal off or reuse. Ten bacterial strains with biodegradation potential were isolated from UEO-contaminated soil sample using enrichment technique. Two strains which exhibited the highest degradation $\%, 51 \pm 1.2$ and $48 \pm 1.5$, respectively, were selected. Based on the morphological, biochemical characteristics and 16S rRNA sequence analysis, they were identified as Ochrobactrum anthropi HM-1 (accession no: KR360745) and Citrobacter freundii HM-2 (accession no: KR360746). The different conditions which may influence their biodegradation activity, including UEO concentration $(1-6 \%, \mathrm{v} / \mathrm{v})$, inoculum size $(0.5-4 \%$, v/v), initial $\mathrm{pH}(6-8)$, incubation temperature $\left(25-45^{\circ} \mathrm{C}\right)$, and rotation speed (0-200 rpm), were evaluated. The optimum conditions were found to be $2 \%$ UEO, $2 \%$ inoculum size, $\mathrm{pH} 7.5$, incubation temperature $37{ }^{\circ} \mathrm{C}$, and $150 \mathrm{rpm}$. Under the optimized conditions, strains HM-1, HM-2, and their mixture efficiently degraded UEO, they achieved $65 \pm 2.2$, $58 \pm 2.1$, and $80 \pm 1.9 \%$, respectively, after 21 days of incubation. Biodegradation of UEO was confirmed by employing gas chromatography analysis. Gamma radiation $(1.5 \mathrm{kGy})$ enhanced the degradation efficiency of irradiated bacterial mixture $(95 \pm 2.1 \%)$ as compared to non-irradiated $(79 \pm 1.6 \%)$. Therefore, strains HM-1 and HM-2 can be employed to develop a cost-effective method for bioremediation of used engine-oil-polluted soil.
\end{abstract}

Haytham M. M. Ibrahim

haythammibrahim@yahoo.com

1 Radiation Microbiology Department, National Center for Radiation Research and Technology (NCRRT), Atomic Energy Authority, 3 Ahmed El Zomor St., Nasr City, P.O. Box 29, Cairo 11371, Egypt
Keywords Used engine oil · Biodegradation . Ochrobactrum anthropi $\cdot$ Citrobacter freundii

\section{Introduction}

Pollution due to petroleum hydrocarbons and its derivatives, including diesel fuel, gasoline, heavy oil, motor oil, fuel residues, and mineral oil, has an increasing influence on the environmental reconquest (Su et al. 2011). They have been recognized as one of the most hazardous wastes (Udeani et al. 2009). Motor oil is a mixture of base lubricant oil and additives, and the base oil contains long-chain $\left(\mathrm{C}_{16}-\mathrm{C}_{36}\right)$ saturated hydrocarbons and more than $75 \%$ cyclic alkanes (Koma et al. 2003). One billion gallons of waste lubricating oil (also called spent oil) are generated during oil-changing processes from automobile and mechanical workshops, a few of this huge amount is recycled, and most is disposed off by incineration or dumping. Therefore, there is a need to appropriate recycling to avoid their dangerous threat towards the environment (Kalyani and Pandey 2014). Used motor oil contains more metals, toxic, and carcinogenic polycyclic aromatic hydrocarbons (PAHs). Thus, it constitutes a potential threat to humans, animals, and vegetation (Adelowo et al. 2006). Treatment of contaminated soil and water resources takes place using mechanical methods, such as skimming and chemical methods, such as surfactants and dispersants; nevertheless, these methods are costly and with limited efficiency (Huang et al. 2008). In contrast, the utilization of microorganisms to degrade such pollutant has been found to be a promising alternative (Akio et al. 2006). Microorganisms have potential to detoxify hazardous organic compounds by means of polymerization, mineralization, or transformation (Sarma and Sarma 2010). Therefore, as 
compared to other technologies, microbial degradation (bioremediation) is the method of choice, because it is costeffective, safe, and environmentally accepted (Singh et al. 2009). Bioremediation process depends on the ability of microorganisms to remove the hydrocarbon pollutants completely (Gómez et al. 2007). Interestingly, numerous hydrocarbon-degrading microorganisms are capable of producing biosurfactants/emulsifiers agents that could increase the solubility of these sparingly or insoluble substrates and facilitate their utilization as sole carbon sources (Franzetti et al. 2010; Su et al. 2011).

Several reports have been established on biodegradation of petroleum hydrocarbons of used engine-oil-contaminated soils. Husaini et al. (2008) had successfully demonstrated the ability of 18 indigenous fungal isolates, isolated from local motor-oil-contaminated areas that were capable of degrading the aliphatic hydrocarbons. Penicillium species (P1) completely degrades the $n$-alkanes in the used motor oil after 2 months of incubation. Su et al. (2011) demonstrated the motor-oil-degrading potential of an indigenous Pseudomonas aeruginosa SU-1 bacterial strain. This bacterium was found to have the ability to degrade motor oil efficiently upon growing in a medium containing such pollutant as the sole carbon source. Bhattacharya et al. (2015) reported that a newly isolated Ochrobactrum sp. C1 could grow with waste lubricants, as the sole carbon and energy source and degrade a wide range of hydrocarbons present in this waste efficiently. Larik et al. (2016) reported the biodegradation of used engine oil and diesel oil using an efficient bacterial consortium A2457: encompassing Stenotrophomonas maltophilia, Bacillus pumilus, and $B$. cereus. Salam (2016) in his study established the extensive degradation ability of two Pseudomonas aeruginosa strains RM1 and SK1 on waste engine oil. He reported the potentials of these strains in the degradation of aromatic, aliphatic, and branched alkane components of waste engine oils. Microbial consortiums have been usually suggested for complete biodegradation of petroleum pollutants (Farahat and El-Gendy 2008), since the constituents of hydrocarbon mixtures differ in their solubility, volatility, and susceptibility to biodegradation, and in contrast, the required sets of enzymes cannot be present in a single microbial strain.

To treat contaminated areas, it is important to employ microorganisms which are indigenous to the contaminated sites and provide excellent degradation potential. Therefore, this work aims to isolate, identify, and characterize native used engine oil utilizing bacterial strains, from UEO-contaminated soil samples, and to estimate the biodegradation potential of the most promising strains, both individually and in combination. In addition, the factors which influence the biodegradation potential of such pollutant were investigated. In an attempt to enhance the biodegradation efficiency of these strains, the effect of gamma radiation was also evaluated.

\section{Materials and methods}

\section{Collection of soil samples}

Three soil samples (each of $100 \mathrm{~g}$ ), from locations that had heavy spillage of used engine oil, were collected in sterile polyethylene bags; from a depth of $15 \mathrm{~cm}$, after removing the surface layer. The samples were transferred to the laboratory and kept at $4{ }^{\circ} \mathrm{C}$ until used for isolation of used engine-oil-degrading bacteria. The soil samples were blackish in color.

\section{Physicochemical characteristics of soil samples}

The $\mathrm{pH}$ of the soil samples was determined with a $\mathrm{pH}$ meter (3505 Jenway UK). Moisture and total organic contents were determined gravimetrically. Heavy metals composition of the soils was estimated using atomic absorption spectrophotometer following mixed acid digestion and extraction of the soil samples. The total hydrocarbons content of the soil was extracted using $n$ hexane: dichloromethane solvent systems (1:1, v/v) according to the method described by Obayori et al. (2008).

\section{Used engine oil (UEO)}

UEO samples $(250 \mathrm{~mL})$ were collected from a local mechanic workshop in sterile $500-\mathrm{mL}$ screw cap glass bottles. Oil samples was transferred to the laboratory and stored in the refrigerator until use. The oil was blackish brown in color. The heavy metals content of UEO was determined using atomic absorption spectrophotometer.

\section{Medium composition}

The base medium used throughout this study was based on the mineral salts medium (MSM) described by Wongsa et al. (2004), and this medium contains the following in g/L: $4.0 \quad \mathrm{NH}_{4} \mathrm{NO}_{3}, 4.7 \quad \mathrm{KH}_{2} \mathrm{PO}_{4}, 0.119 \mathrm{Na}_{2} \mathrm{HPO}_{4}, 0.01$ $\mathrm{CaCl}_{2} \cdot 2 \mathrm{H}_{2} \mathrm{O}, 1.0 \mathrm{MgSO}_{4} \cdot 7 \mathrm{H}_{2} \mathrm{O}, 0.01 \mathrm{MnSO}_{4} \cdot 4 \mathrm{H}_{2} \mathrm{O}$, and $0.015 \mathrm{FeSO}_{4} \cdot 4 \mathrm{H}_{2} \mathrm{O}$. The MSM was amended with yeast extract $(0.005 \mathrm{~g} / \mathrm{L})$ to increase the rate of biodegradation. $\mathrm{pH}$ was adjusted to 7.0 using $1 \mathrm{~N} \mathrm{HCl} / \mathrm{NaOH}$ prior to sterilization by autoclave at $121{ }^{\circ} \mathrm{C}$ for $20 \mathrm{~min}$.

\section{Isolation of UEO-degrading bacteria}

UEO-degrading bacteria were isolated employing the culture enrichment method as follows: Oil-contaminated soil 
sample $(10 \mathrm{~g})$ was added to sterile MSM $(100 \mathrm{~mL})$, supplemented with UEO $(1 \%, \mathrm{v} / \mathrm{v})$ as the sole carbon source, in 250-mL Erlenmeyer flasks, and incubated in a rotary shaker incubator (Gallen Kamp, UK) at $32{ }^{\circ} \mathrm{C}$ and $150 \mathrm{rpm}$ for 15 days. Later, $2 \mathrm{~mL}$ inoculum was transferred to a fresh MSM and incubated for another cycle. After three successive transfers, $1 \mathrm{~mL}$ of the culture was serially diluted in sterile saline solution $(9 \% \mathrm{NaCl})$. A $100 \mu \mathrm{L}$ of the appropriate dilutions were plated onto sterile MSM agar plates previously sprayed with a UEO solution ( $2 \mathrm{~g} /$ $20 \mathrm{~mL}$ in dichloromethane) and left uncovered in laminar air flow until the solvent has evaporated. The plates were incubated at $32{ }^{\circ} \mathrm{C}$, and the developed bacterial colonies were selected based on their ability to grow and utilize UEO as sole carbon and energy source. Pure colonies on nutrient agar slants were properly labeled, preserved at $4{ }^{\circ} \mathrm{C}$, and subcultured at 4 week interval.

\section{Oil degradation potential of selected isolates}

A single colony of each selected isolate was inoculated into $25 \mathrm{~mL}$ nutrient broth medium (Oxoid) in 250-mL flask, and incubated in a shaker incubator (Gallen Kamp, UK) at $32{ }^{\circ} \mathrm{C}$ and $150 \mathrm{rpm}$ for $18 \mathrm{~h}$. Following incubation, the cells were separated by centrifugation at $10.000 \times g$ and $4{ }^{\circ} \mathrm{C}$ for $20 \mathrm{~min}$ using GL-18B refrigerated centrifuge (USA), and the pellets were washed twice with sterile normal saline solution and resuspended in fresh sterile MSM. One millilitre of the bacterial suspensions was used as an inoculum; to obtain standard inocula, the optical density (O.D ${ }_{660}$ ) was fixed to 0.5 (Ghazali et al. 2004) using UV-Vis spectrophotometer (Helios Gamma, Thermo Corporation, England), and uninoculated MSM was used as a blank to adjust the spectrophotometer reading to zero. To determine the biodegradation potential, $2 \mathrm{~mL}$ of each bacterial suspension was inoculated into MSM $(100 \mathrm{~mL})$, supplemented with UEO $(2 \%, \mathrm{v} / \mathrm{v})$, and incubated as aforementioned for 15 days. The UEO was sterilized separately by filtration. Control experiments (without bacterial biomass and with inactivated biomass by sterilization to assess the adsorption phenomena of substrate to the bacteria) were run simultaneously to assess the abiotic degradation of UEO. Thus, the values of the abiotic controls were subtracted from biotic degradation efficiencies, to report only the degradation caused by living bacterial cells.

\section{Analytical methods}

\section{Evaluation of bacterial growth}

The bacterial growth was evaluated by measuring the optical density $\left(\mathrm{O}^{-\mathrm{D}_{660}}\right)$ using $\mathrm{UV}-\mathrm{V}$ is spectrophotometer (Helios Gamma, Thermo Corporation, England).

\section{Total petroleum hydrocarbons (TPH) determination}

TPH were determined spectrophotometrically based on the method of Darvishi et al. (2011). Each sample was mixed with an equal volume of hexane, shaken vigorously for 2 min on vortex, and then centrifuged at $10.000 \times g$ and $4{ }^{\circ} \mathrm{C}$ for $15 \mathrm{~min}$. The hexane phases were collected, and the TPH contents were determined by measuring the absorbance at $272 \mathrm{~nm}$ using UV-Vis spectrophotometer, and this wavelength was chosen depending on the previous investigation performed using a mixture of UEO/hexane, which showed the highest absorbance at $272 \mathrm{~nm}$. Following the same procedure, a standard curve was prepared using known concentrations of UEO $(0.5-5 \mathrm{mg} / \mathrm{L})$. Accordingly, the relationship between the UEO concentration and the absorbance was as follows:

$Y=1.0641 X$

where $Y$ is the measured absorbance of sample $\left(\mathrm{AB}_{272 \mathrm{~nm}}\right)$ and $X$ is the concentration of UEO in the sample.

Degradation percentage was determined as the difference between the initial and final TPH concentrations as follows:

Degradation $(\%)=\left[\left(O_{\mathrm{i}}-O_{\mathrm{r}}\right) / O_{\mathrm{i}}\right] \times 100 \%$

where $O_{\mathrm{i}}$ is the initial UEO concentration $(\mathrm{mg} / \mathrm{L})$ and $O_{\mathrm{r}}$ is the residual concentration.

\section{Gas chromatography (GC) analysis}

Hexane extracts of residual oil samples were injected into a G-1000 chromatographic analyzer (Dani, Italy) equipped with HP-5 column $\left(30 \times 10^{3} \mathrm{~cm}\right.$ in length; $0.032 \mathrm{~cm}$ in internal diameter; and $1 \times 10^{-3} \mathrm{~cm}$ in film thickness) and a flame ionisation detector. The operation conditions were sample size $(1 \mu \mathrm{L})$, nitrogen was used as the carrier gas, the injector and detector temperatures were maintained at $300{ }^{\circ} \mathrm{C}$ and $280{ }^{\circ} \mathrm{C}$, respectively, and the oven was programmed at an initial temperature of $40{ }^{\circ} \mathrm{C}$; this was held for $2 \mathrm{~min}$, then ramped at $15^{\circ} \mathrm{C} / \mathrm{min}$ to $300{ }^{\circ} \mathrm{C}$ and held for $10 \mathrm{~min}$. Degradation of UEO was demonstrated by comparing the TPH peaks area of oil residues in inoculated flasks with that from uninoculated control flasks (Bhattacharya and Biswas 2014).

\section{Screening for biosurfactant production}

\section{Oil displacement assay}

Oil displacement test was accomplished, as described by Morikawa et al. (2000). To a Petri plate containing $20 \mathrm{ml}$ of distilled water, a $20 \mu \mathrm{L}$ of crude petroleum oil was 
added, forming a thin film on the water surface. Then, $10 \mu \mathrm{L}$ of cell-free culture supernatants was gently put into the center of oil film. If a biosurfactant is present, the oil will be displaced with an oil-free clearing zone; the diameter of this clearing zone indicates the oil displacement activity of the biosurfactant. Distilled water was employed as the negative control, in which no oil displacement or clear zone was observed. Triton X-100 was used as the positive control.

\section{Emulsification activity $\left(\mathbf{E}_{24}\right)$}

A mixture of $4 \mathrm{ml}$ culture supernatants and $4 \mathrm{ml}$ used motor oil was mixed by vortex for $3 \mathrm{~min}$ and left to stand for $24 \mathrm{~h}$ at $25{ }^{\circ} \mathrm{C}$ prior to measurement. $E_{24}$ was expressed as the percentage of the height of the emulsified layer divided by the total height of the liquid column as given by the following formula (Sarubbo 2006):

$E_{24}(\%)=\frac{\text { The height of emulsion layer }}{\text { The height of total solution }} \times 100$

\section{Heavy metal tolerance test}

Heavy metal tolerance of strains HM-1 and HM-2 was determined as described by Salam (2016). The strains were grown in nutrient broth overnight at $32{ }^{\circ} \mathrm{C}$ and $150 \mathrm{rpm}$ in a rotary shaking incubator (Gallen Kamp, UK). Cells were harvested by centrifugation $(5000 \times g ; 15 \mathrm{~min})$, washed twice with sterile phosphate buffer, and resuspended in the same buffer solution. The cell concentration of bacterial suspensions was adjusted at 0.8 by measuring the optical density of the samples at $660 \mathrm{~nm}$. Stock solutions $(1 \mathrm{M})$ of metal salts, namely, $\mathrm{NiSO}_{4}, \mathrm{~Pb}\left(\mathrm{NO}_{3}\right)_{2}$, and $\mathrm{Zn}\left(\mathrm{NO}_{3}\right)_{2}$ were prepared in distilled water, filter sterilized using $0.22-\mu \mathrm{m}$ membrane filters, and stored in sterile bottles in the dark at $4{ }^{\circ} \mathrm{C}$. Dilutions to $1,5,10$, and $15 \mathrm{mM}$ of $\mathrm{Zn}^{2+}, \mathrm{Ni}^{2+}$, and $\mathrm{Pb}^{2+}$ were made from the stock solutions into nutrient broth. The media were dispensed in 5-ml aliquots and inoculated with $50 \mu \mathrm{L}$ inoculum. Each of the experiment was conducted in triplicates. Nutrient broth without inocula and heavy metals was used as control. Bacterial growth was measured by absorbance at $660 \mathrm{~nm}$. The maximum tolerance concentration (MTC) for the strains, defined as the highest concentration of metal which do not affect the growth, was determined after incubation for 7 days.

\section{Identification of bacterial isolates}

\section{Morphological and biochemical properties}

The selected bacterial isolates (HM-1 and HM-2) were identified and characterized according to Bergey's Manual of Determinative Bacteriology (Holt et al. 1998). Morphological characteristics included colony color, Gram staining, spore formation, and motility. In contrast, biochemical tests involved starch hydrolysis, citrate utilization, oxidase production, methyl red test, Voges-Proskauer test, gelatin liquefaction test, fermentation of carbohydrates, production of hydrogen sulfide test, urease test, indole production test, nitrate reduction, and lipid hydrolysis test.

\section{S rRNA sequencing and species identification}

Amplification and sequencing of the 16S rRNA gene were performed at Macrogen Biotech Co., Ltd, South Korea. Amplification was performed by polymerase chain reaction (PCR) using DNA Engine Tetrad 2 Peltier Thermal Cycler (BIO-RAD), with the following sets of universal primers 27F (5'-AGAGTTTGATCMTGGCTCAG-3') and 1492R (5'TACGGYTACCTTGTTACGACTT- $3^{\prime}$ ), synthesized by Macrogen Biotech Co., Ltd, South Korea. The PCR products were sequenced using ABI PRISM Big Dye Terminator Cycle Sequencing Kit (Applied BioSystems, USA), with the following sets of universal primers: 518F (5'-CCAGCAGCCGCGGTAATACG- $\left.3^{\prime}\right)$ and 800R (5'-TACCAGGGTATCTAATCC- $3^{\prime}$ ). Sequencing products were resolved on an Applied Biosystems model 3730XL automated DNA sequencing system (Applied BioSystems, USA). Alignment similarities of 16S rRNA gene sequences, sorted by the E score, were done with BLAST search of the National Centre for Biotechnology Information (NCBI) server (www.ncbi.nlm.nih.gov/BLAST). The 16S rRNA gene sequences were submitted to the GenBank. Analysis of the 16S rRNA gene sequences data was performed using the software package MEGA version 6, and the phylogenetic tree was inferred using neighbor-joining methods.

\section{Investigation of biodegradation conditions}

Oil biodegradation efficiency of strains HM-1 and HM-2 as well as their mixture (with equal volumes) was investigated under various culture and environmental conditions, including the initial UEO concentration $(1,2,4$, and $6 \%$, $\mathrm{v} / \mathrm{v})$, the inoculum size $(0.5,1,2$, and $4 \%, \mathrm{v} / \mathrm{v})$, the initial medium $\mathrm{pH}(6,7,7.5$, and 8$)$, incubation temperature $(25$, 32,37 , and $\left.45^{\circ} \mathrm{C}\right)$, and rotation speed $(0,100,150$, and $200 \mathrm{rpm})$. Under the optimum conditions, the time course of UEO degradation by strains HM-1 and HM-2, and their mixture was determined throughout 21 days. After every 3 days interval of incubation, samples were drawn from each flask for the analysis of bacterial growth and UEO degradation \%. All experiments were performed in triplicate. 


\section{Influence of gamma irradiation}

Gamma irradiation process was carried out in the National Center for Radiation Research and Technology (NCRRT), using ${ }^{60} \mathrm{Co}$ irradiation facility (Gamma Cell 220 Excel, MDS Nordion, Canada). The dose rate was $2.164 \mathrm{kGy} / \mathrm{h}$ at the time of experiment. The bacterial strains were inoculated into $50 \mathrm{~mL}$ nutrient broth (Oxoid) and incubated for $18 \mathrm{~h}$. Later, aliquots $(1 \mathrm{~mL})$ of the culture broth $\left(\mathrm{O}_{\mathrm{D}} \mathrm{D}_{60}=0.5\right)$ were transferred into test tubes containing $9 \mathrm{~mL}$ sterile saline solution. The suspensions were then exposed to different doses of gamma radiation $(0.5,1,1.5$, 2, 2.5, and $3 \mathrm{kGy}$ ). Afterward, $1 \mathrm{~mL}$ of irradiated cells suspensions was inoculated into fresh MSM (100 mL) and enriched with UEO ( $2 \%, \mathrm{v} / \mathrm{v})$. The flasks were incubated as aforementioned. Later, the residual oil was extracted and quantified as mentioned earlier. The efficiency of the irradiated cells was compared with that of the control (nonirradiated) cells.

\section{Statistical analysis}

All experiments were performed in triplicate, and the results are presented as means \pm standard deviations. Analysis of variance (ANOVA) was used to compare different variables. All analyses were done using the Statistical Analysis Software (SAS) 9.0.

\section{Results and discussion}

\section{Physicochemical characteristics of soil samples}

The physicochemical properties of the soil samples were performed to determine the physical factors, limiting nutrients, and pollutants that could indicate the types of microorganisms recovered from the soils. The $\mathrm{pH}$ of the three soil samples was weakly acidic (5.7-6.3). The presence of various heavy metals, such as lead, zinc, cadmium, iron, and nickel, emphasized the pollution of the soil samples (Table 1).

\section{Heavy metals analysis of used engine oil}

The spectrophotometric analysis of used engine oil demonstrated the presence of several heavy metals, including the following in (mg/l): lead (2.5), nickel (23.4), iron (14), manganese (0.35), copper (0.18), and zinc (55.7).

\section{Isolation of UEO-degrading bacteria}

Employing enrichment technique and plate separation, ten bacterial isolates with apparent clear zones were selected,
Table 1 Physicochemical characteristics of soil samples

\begin{tabular}{lrcc}
\hline Parameter & Sample 1 & Sample 2 & Sample 3 \\
\hline pH & 6.3 & 5.7 & 6.0 \\
Moisture (\%) & 8.21 & 8.36 & 7.56 \\
Total organic carbon (\%) & 2.01 & 1.58 & 1.80 \\
Total hydrocarbon content (mg/kg) & 146.12 & 152.30 & 188.55 \\
Iron (mg/kg) & 21.10 & 10.53 & 23.11 \\
Lead (mg/kg) & 0.15 & 0.18 & 0.21 \\
Zinc (mg/kg) & 1.14 & 0.48 & 1.20 \\
Copper (mg/kg) & 4.20 & 3.11 & 2.45 \\
Manganese (mg/kg) & 2.25 & 1.56 & 3.13 \\
Cadmium (mg/kg) & 2.10 & 1.58 & 1.20 \\
Nickel (mg/kg) & 4.21 & 2.53 & 3.33 \\
\hline
\end{tabular}

picked up, and purified. These isolates were designated as HM-1 to HM-10.

\section{Screening of UEO degrader bacteria}

As shown in Fig. 1, among the ten bacterial isolates and with degradation potential of more than $45 \%$, only two isolates, namely, HM-1 and HM-2, efficiently utilized UEO as the sole carbon and energy source, and they showed superior growth; the O.D 660 was $1.3 \pm 0.1$ and $0.95 \pm 0.2 \%$, respectively. Besides, they revealed the best degradation efficiency, $51 \pm 1.2$ and $48 \pm 1.5 \%$, respectively. The other isolates were not further selected and separated because of their low degradability of UEO. Nominal oil degradation $(3 \pm 0.5 \%$ ) was obtained in the abiotic control flasks. During incubation, emulsification of UEO was evident in the culture media, suggesting the production of extracellular biosurfactant/bioemulsifier, which may be one of the mechanisms used by these strains to utilize UEO. Both isolates emulsified the UEO within only 5 days of incubation; on standing the flask, a thin layer of oil was separated out which again became dispersed on gentle shaking. In contrast, the oil layer in control flasks remained on the surface even after 15 days. In a similar study, the strain Ochrobactrum sp. C1 was found to tolerate unusually high waste engine oil concentration together with emulsification ability of the culture broth medium, and its degradation competence was $48.5 \pm 0.5 \%$ (Bhattacharya et al. 2015).

\section{Screening for biosurfactant production}

Since production of biosurfactant/emulsifier is one of the mechanisms responsible for enhanced biodegradation of water immiscible pollutants, such as UEO, two simple and preliminary tests were employed to determine the ability of strains HM-1 and HM-2 to produce biosurfactant in the 
Fig. 1 Growth and biodegradation potential of the selected bacterial isolates. Error bars represent SD values of three independent experiments $(n=3)$

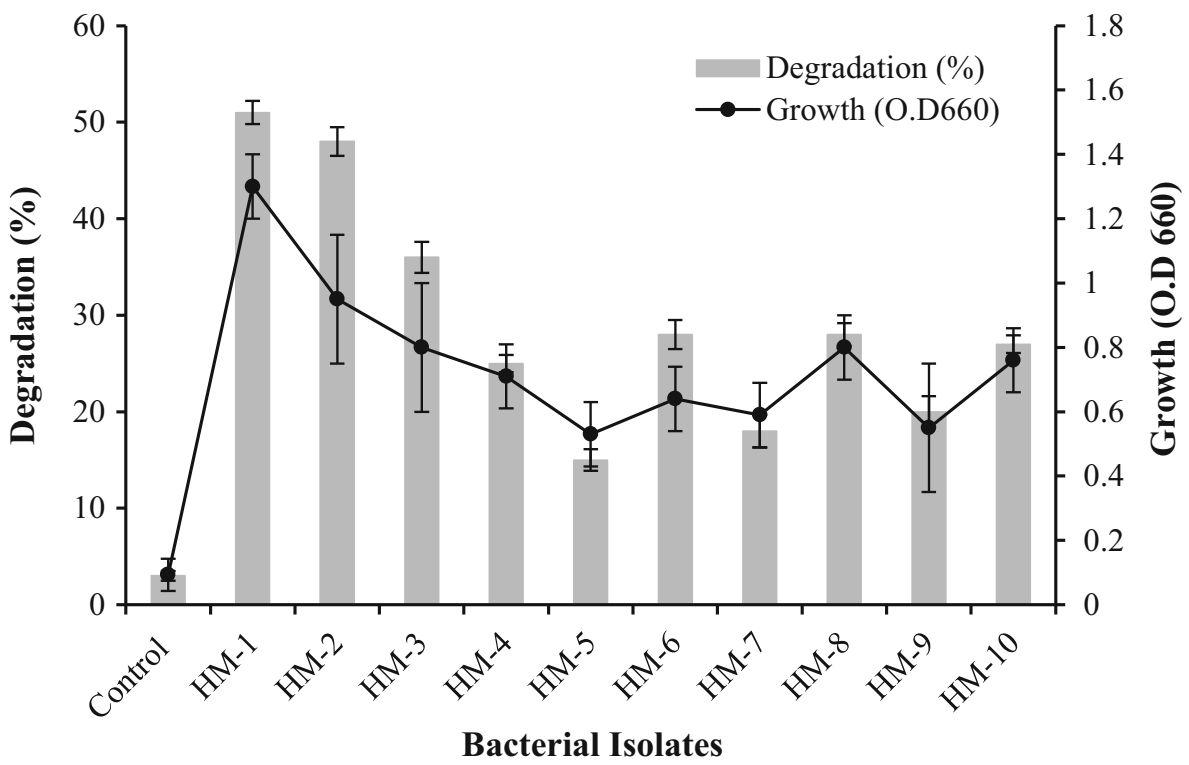

culture medium. The cell-free culture supernatants of $O$. anthropi HM-1 and $C$. freundii HM-2 showed high surface activity, and the diameter of displaced circles was 7 and $6.5 \mathrm{~cm}$, with concomitant circles area of 38.5 and $33.17 \mathrm{~cm}^{2}$, respectively. Similarly, the cell-free culture supernatants revealed high $\mathrm{E}_{24}$, namely, 90 and $89 \%$, respectively. Based on these preliminary screening results, it could be stated that strains HM-1 and HM- 2 can produce biosurfactants and secrete them extracellularly in the growth medium, and hence, it confirm the speculation of biosurfactant-enhanced biodegradation by these strains. Similarly, Larik et al. (2016) reported the biodegradation of used engine oil and diesel oil under shake flask conditions using an efficient bacterial consortium A2457: comprising bacterial strains of Stenotrophomonas maltophilia, Bacillus cereus, and Bacillus pumilus. They attributed this biodegradation potential to the production of biosurfactants and lipases to utilize diesel oil and used engine oil as sole source of carbon and energy.

\section{Metal tolerance of used engine-oil-degrading strains}

Metal tolerance experiment of strains HM-1 and HM-2 on diverse heavy metals was performed to determine their resistance limit to different concentrations of heavy metals used. The results showed that strains HM-1 and HM-2 resisted zinc, lead, and nickel at (1-15 mM), (1-5 mM), and $(1-10 \mathrm{mM})$, respectively.

\section{Identification of UEO-degrading bacteria}

Following plating on the nutrient agar medium and incubation at $32{ }^{\circ} \mathrm{C}$ for $48 \mathrm{~h}$, the developed colonies, of both
Table 2 Morphological and biochemical characteristics of the UEOdegrading bacterial isolates

\begin{tabular}{lll}
\hline Characteristics & \multicolumn{2}{l}{ Bacterial isolate } \\
\cline { 2 - 3 } & HM-1 & HM-2 \\
\hline Color of colonies & White & Creamy-white \\
Shape & Short rods & Rods \\
Motility & + & + \\
Gram straining & - & - \\
Aerobic growth & + & + \\
Spore formation & - & - \\
Catalase activity & + & + \\
Glucose fermentation & - & + \\
Lactose utilization & + & + \\
Oxidase test & + & - \\
Nitrate reduction & - & + \\
Starch hydrolysis & + & + \\
Gelatin hydrolysis & - & - \\
Tween 80 hydrolysis & - & - \\
Urease hydrolysis & + & - \\
Indole production & - & - \\
Methyl red test & - & + \\
Voges-Proskauer reaction & - & - \\
Citrate utilization test & + & + \\
Hydrogen sulfide test & - & - \\
\hline
\end{tabular}

isolates, were white or creamy-white in color, translucent, convex, with entire margins, smooth surfaces, and $1.5-1.8 \mathrm{~mm}$ in diameter. As given in Table 2, the isolates were Gram-negative, non-spore former, rods/short rods, motile, catalase positive, lactose utilization positive, starch 
hydrolysis positive, and citrate utilization positive. However, there are some differences between the two isolates, as indicated in Table 2. On the basis of the above characteristics, the isolates HM-1 and HM-2 were tentatively identified as Ochrobactrum sp. and Citrobacter sp., respectively.

To confirm the results of biochemical and morphological identification, the partial 16S rRNA gene sequences of the two isolates were determined. The 16S rRNA gene sequences of strains HM-1 and HM-2 were a continuous stretch of 996 and 1000 bp, respectively. Database comparison using BLAST program revealed that strains HM-1 and HM-2 had a high similarity of $99 \%$ with those of strains Ochrobactrum anthropi (GenBank accession no. AB841124) and Citrobacter freundii (GenBank accession no. NR 028894), respectively. Based on the phylogenetic trees, the closest relatives of strains HM-1 and HM-2 were O. anthropi (GenBank accession no. AB841124) (Fig. 2a) and $C$. freundii strain ATCC 8090 (GenBank accession no. NR 028894) (Fig. 2b), respectively. Thus, strains HM-1 and HM-2 were designated as $O$. anthropi HM-1 and $C$. freundii HM-2, respectively. The $16 \mathrm{~S}$ rRNA gene sequences of $O$. anthropi $\mathrm{HM}-1$ and $C$. freundii $\mathrm{HM}-2$ were deposited in the GenBank under accession numbers KR360745 and KR360746, respectively.
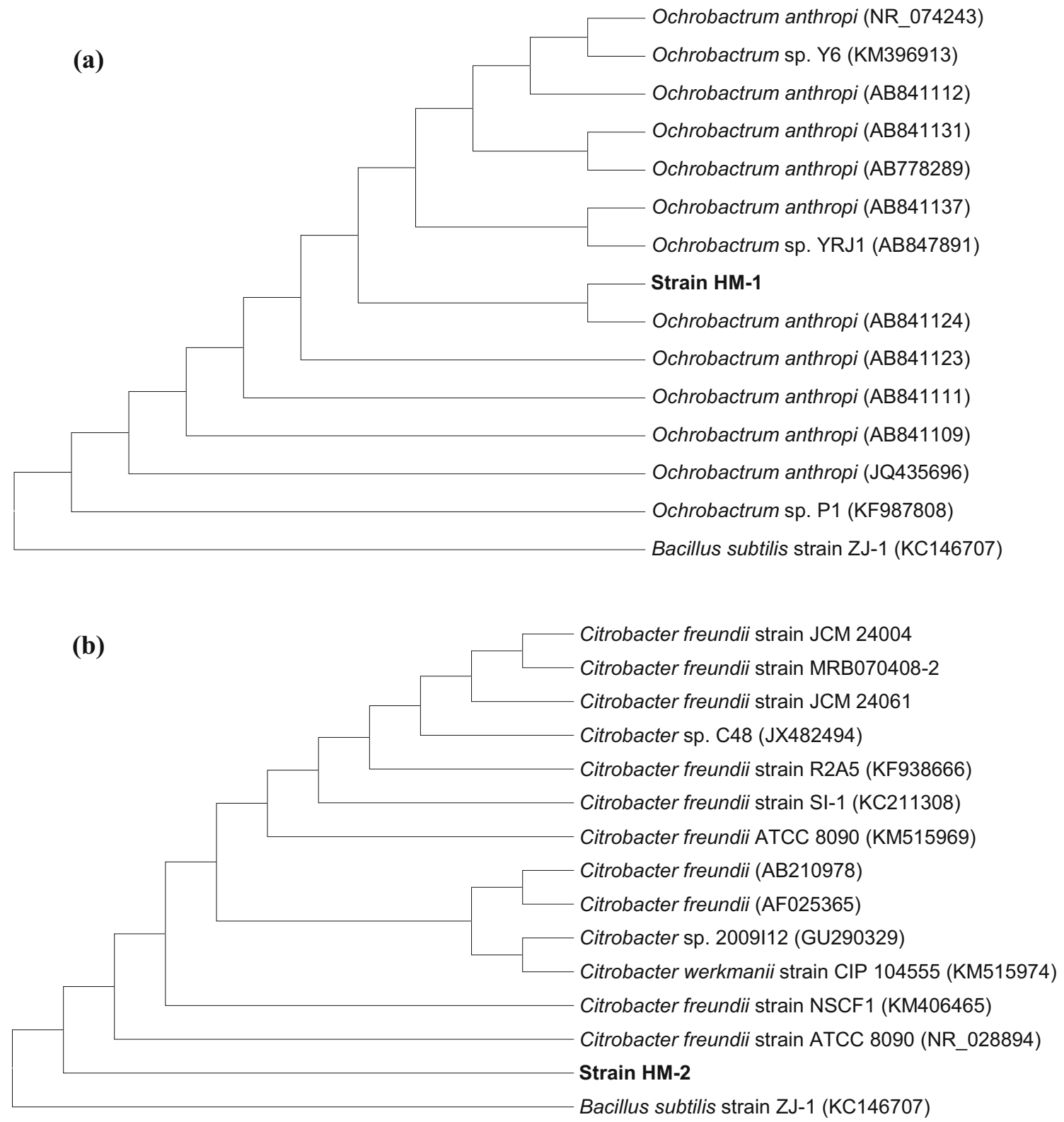

Fig. 2 Phylogenetic tree of the 16S rRNA sequences of $O$. anthropi strain HM-1 (a) and $C$. freundii strain HM-2 (b). The calculations were performed according to a neighbor-joining algorithm (bootstrap number $=1000$ ), and the scale bar represents 0.001 sequence divergence. Data in parentheses are the GenBank accession numbers 


\section{UEO degradation conditions of selected strains}

The degradation conditions of UEO were investigated. As illustrated in Fig. 3a, the highest biodegradation percentage was obtained at an initial oil concentration of $1 \%(\mathrm{v} / \mathrm{v})$ followed by $2 \%$. The degradation percentage at $1 \%$ was $72 \pm 1.4,61 \pm 1.3$ and $85 \pm 1.7 \%$, for $O$. anthropi HM-

\section{(a)}

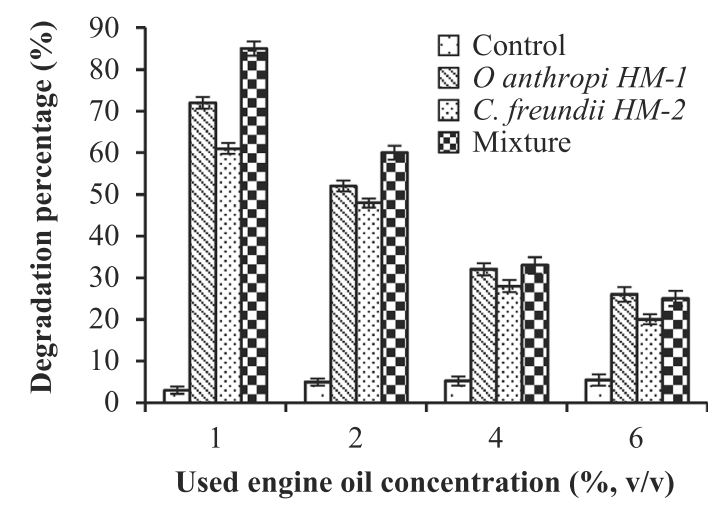

(c)

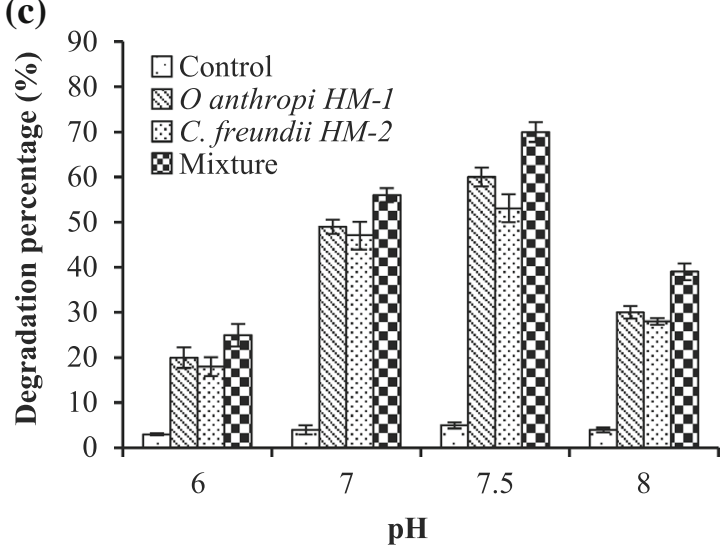

(e)

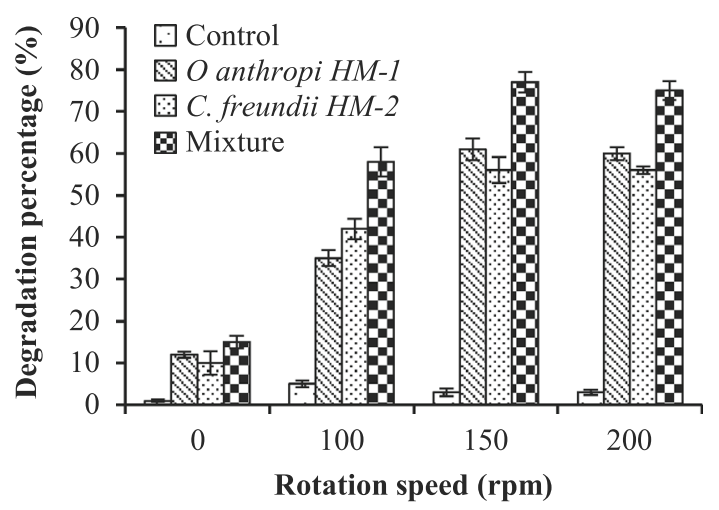

Fig. 3 Effect of different cultivation conditions on the biodegradation efficiency of $O$. anthropi HM-1, C. freundii HM-2, and their mixture: used engine oil initial concentration (a), inoculum size (b),
1, C. freundii HM-2, and their mixture, respectively. At higher UEO concentration (4 and $6 \%$ ), the degradation percentage decreased significantly, and this decrease could be ascribed to the toxicity of UEO at such concentrations, which might have negative effects on the biodegradation activities of the tested bacterial strains (Abioye et al. 2012). In contrast, for all controls, no significant reduction in oil

(b)
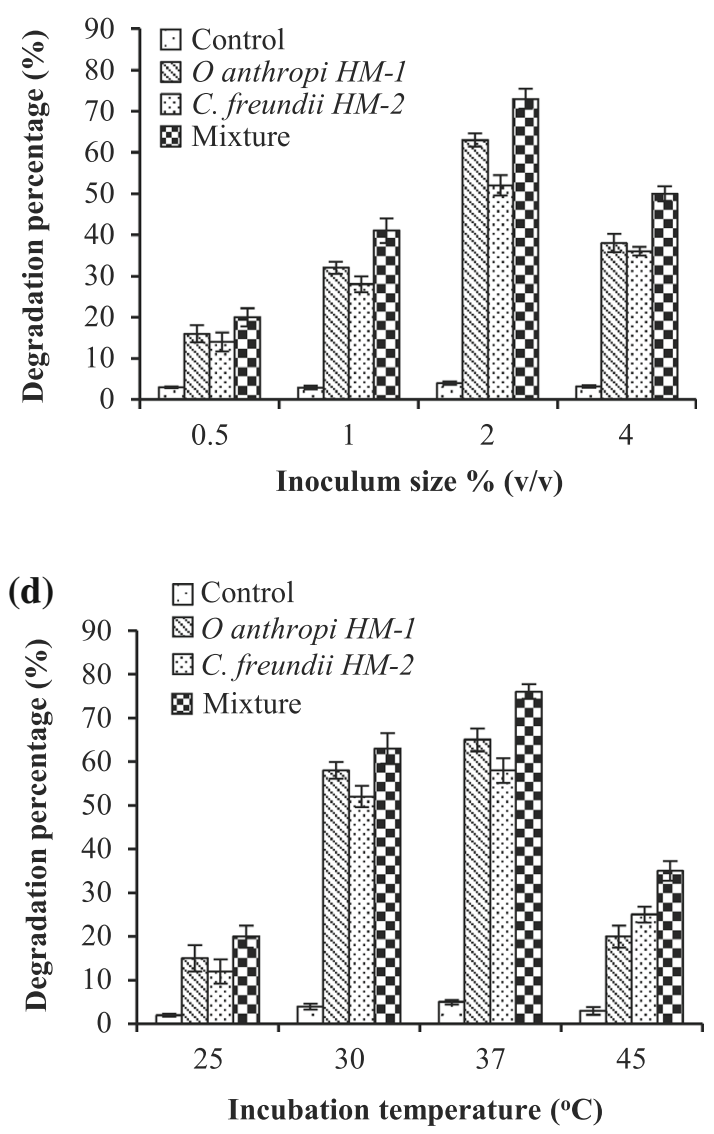

medium $\mathrm{pH}(\mathbf{c})$, incubation temperature (d), and rotation speed (e). Error bars represent SD values of three independent experiments $(n=3)$ 
concentration was observed; the degradation percentage ranged from $3 \pm 0.9$ to $5.5 \pm 1.3 \%$. For the further investigations, UEO $(2 \%, \mathrm{v} / \mathrm{v})$ was used. In a similar study, Abioye et al. (2012) reported 3-6\% as the concentration of used motor oil for the maximum rate of biodegradation.

The consumption of nutrients is largely relying on the inoculum size of bacteria; therefore, the bacterial population should be controlled. As illustrated in Fig. 3b, increasing the inoculum size significantly enhanced biodegradation efficiency of tested bacterial strain. The highest degradation percentage was obtained at inoculum size $2 \%(\mathrm{v} / \mathrm{v})$. Strains HM-1, HM-2, and their mixture achieved degradation percentage of $63 \pm 1.6,52 \pm 2.5$, and $73 \pm 2.4 \%$, respectively. Increasing the inoculum size to $4 \%$ resulted in reduced biodegradation percentage. In contrast, no significant reduction in oil concentration was observed for all controls, as pointed out in Fig. 3b. It has been reported that the low inoculum size requires a longer time for cells to multiply and to produce the desired effect (Jin et al. 1998). Similarly, Abusham et al. (2009) mentioned that the small inoculum size can lead to an insufficient number of bacterial cells and a reduced amount of the secreted enzymes, while higher inoculum size could lead to a lack of oxygen and depletion of nutrients in the growth media.

As shown in Fig. 3c, the utilization of UEO was slower when the initial medium $\mathrm{pH}$ was acidic $(\mathrm{pH} 6)$ as revealed by the low degradation percentage. In contrast, the maximum rate of biodegradation process was achieved when the $\mathrm{pH}$ was neutral or slightly alkaline. The highest degradation percentage was observed at $\mathrm{pH} 7.5$, at which $O$. anthropi HM-1, C. freundii HM-2, and their mixture attained degradation percentage of $60 \pm 2.1,53 \pm 3.1$, and $70 \pm 2.2 \%$, respectively. Further increase in medium $\mathrm{pH}$ to 8 led to a remarkable decrease in biodegrading percentage, which may be attributed to the reduced bacterial activity. Only marginal abiotic loss ( $3 \pm 0.2$ to $5 \pm 0.5 \%)$ was observed in the control flasks (Fig. 3c). In good agreement, Bhattacharya et al. (2015) found that the biodegradation of waste lubricants by strain Ochrobactrum sp. C1 was optimized at the initial $\mathrm{pH}$ 7.3. In addition, Deng et al. (2014) reported that the highest degradation rate $(95.6 \%)$ of diesel oil by strain Achromobacter sp. HZ01 occurred at pH 7.5. The obtained results were consistent with the findings of Jain et al. (2010) who reported that the degradation of petroleum hydrocarbons in crude oil was most favorable near neutral $\mathrm{pH}$.

Incubation temperature usually varied from microorganism to another, it greatly affects all the metabolic processes, it can be anticipated to have a significant influence on oil degradation, and consequently, it should be controlled. As indicated in Fig. $3 \mathrm{~d}$, the rate of UEO degradation process was maximum at incubation temperature of 30 and $37^{\circ} \mathrm{C}$; nevertheless, the most favourable temperature for biodegradation was $37^{\circ} \mathrm{C}$, at which $65 \pm 2.6,58 \pm 2.8$, and $76 \pm 1.7 \%$ degradation were achieved by strains HM-1, HM-2, and their mixture, respectively. A noticeable decreasing trend was observed with the further elevation of incubation temperature to $45^{\circ} \mathrm{C}$. Nominal percentage loss of waste oil was observed for all controls $(2 \pm 0.3$ to $5 \pm 0.9 \%)$. In agreement, Aleer et al. (2011) also found that the optimum temperature for waste engine oil biodegradation by a microbial consortium was $30-37{ }^{\circ} \mathrm{C}$.

The variation in the agitation speed affects the degree of mixing and the nutrient availability in the shake flasks or the bioreactor (Abusham et al. 2009). The degradation activity of strains HM-1, HM-2 and their mixture gradually increased and reached the maximum value at rotation speed $150 \mathrm{rpm}$, at which they exhibited degradation percentage of $61 \pm 2.6,56 \pm 3.1$, and $77 \pm 2.5 \%$, respectively (Fig. 3e). The degradation rate did not reveal any increasing tendency with the further increase of rotate speed to $200 \mathrm{rpm}$. Therefore, the optimal rotation speed is $150 \mathrm{rpm}$, which guarantees to maintain a sufficient supply of dissolved oxygen in the medium for the bacterial strains to grow and degrade the UEO. In agreement, Deng et al. (2014) found that the degradation rate of diesel oil using strain Achromobacter sp. HZ01 was gradually increased by increasing the agitation speed and reached the maximum at $150 \mathrm{rpm}$.

It is worth noted that, for all the degradation experiments, the bacterial mixture exhibited higher degradation percentage compared with the individual pure cultures. These results suggested that strains HM-1 and HM-2 could co-exist with no adverse effect and possibly have a synergy, which may be responsible for the high degradation percentage observed in this study. The advantages of employing mixed cultures have been manifested (Akoachere et al. 2008). Ghazali et al. (2004) reported that some species are able to remove the toxic metabolites that prohibit the activities of the other species. Then, it is possible that the other species degrade complex compounds totally.

\section{Time course of UEO biodegradation}

Under the optimum conditions, namely, UEO $2 \%(\mathrm{v} / \mathrm{v})$, $\mathrm{pH} 7.5$, inoculum size $2 \%(\mathrm{v} / \mathrm{v})$, incubation temperature $37^{\circ} \mathrm{C}$, and $150 \mathrm{rpm}$, the growth along with degradation rate of UEO by strains HM-1, HM-2, and their mixture were investigated over 21 days incubation period. As illustrated in Fig. 4a, the bacterial strains started utilization of UEO as sole energy and carbon sources, since the initial 3 days interval. The growth $\left(\right.$ O.D $\left._{660}\right)$ increased rapidly by extending the incubation time, and strain HM-1 attained 


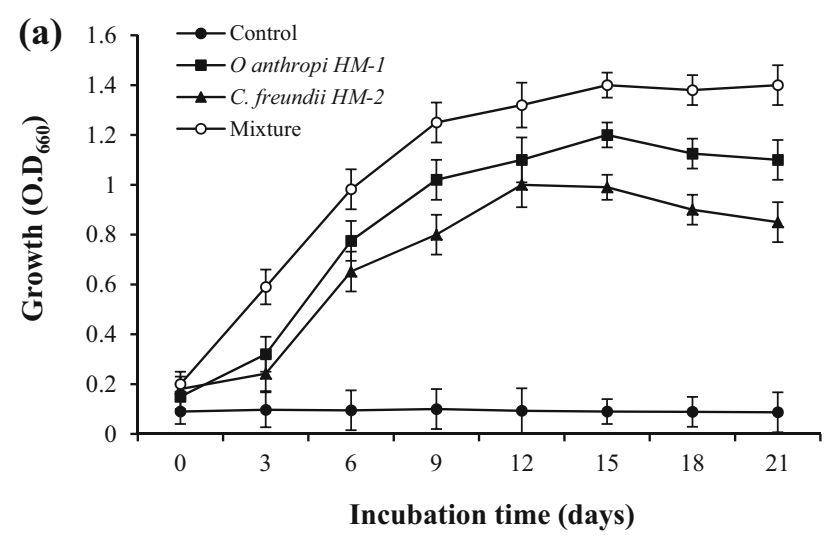

(b)

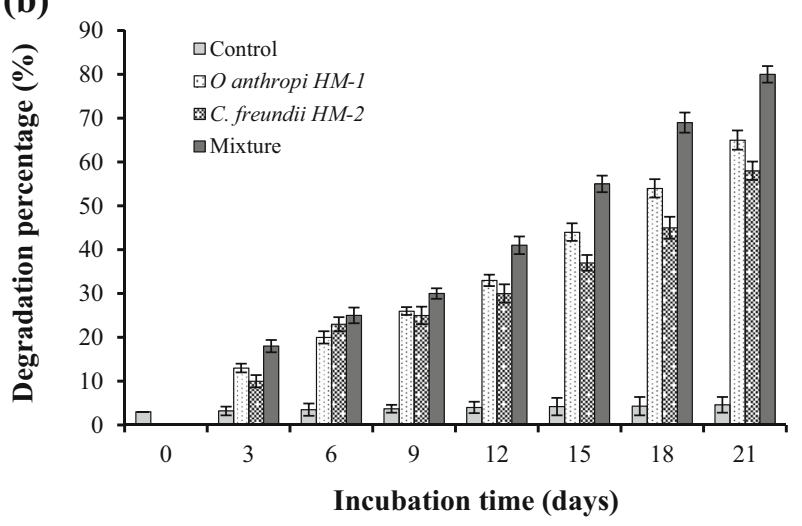

Fig. 4 Time course of UEO biodegradation by the bacterial mixture during 21 days of incubation at the initial oil concentration $2 \%(\mathrm{v} / \mathrm{v})$, inoculum size $2 \%(\mathrm{v} / \mathrm{v})$, medium $\mathrm{pH}(7.5)$, incubation temperature $37{ }^{\circ} \mathrm{C}$, and rotation speed $150 \mathrm{rpm}$

maximum growth after 15 days (max. O.D $D_{660}, 1.2 \pm 0.05$ ) compared with 12 days for strain HM-2 (max. O.D 660 , $1.0 \pm 0.09)$. In contrast, the bacterial mixture continued to grow and utilize UEO until the end of incubation time, the maximum O. $_{660}$ was $1.4 \pm 0.08$. Similarly, the two bacterial strains along with their mixture started degradation of UEO, since the initial 3 days interval (Fig. 4b), and the degradation rate increased with time until reached maximum at the end of incubation period (21 days); $65 \pm 2.2,58 \pm 2.1$, and $80 \pm 1.9 \%$ degradations were attained by strains HM-1, HM-2, and the mixture, respectively. As stated before, the bacterial mixture was more efficient than individual bacterial strains and might be due to synergetic effect.

Larik et al. (2016) reported a significant degradation of the used engine oil $(99.77 \%)$ by the consortium A2457 when grown in MSM amended with UEO at $30{ }^{\circ} \mathrm{C}$ for 28 days in shaking incubator. Bhattacharya et al. (2015) reported an increase in the percentage degradation from 48.35 to $63.5 \%$ for waste engine oil and from 30.74 to $41.5 \%$ for waste transformer oil on increasing the incubation period up to 21 days. Other researchers (Wang et al. 2011; Abioye et al. 2012) also found that total petroleum hydrocarbon levels could be significantly reduced by increasing the incubation period during treatment of waste oil-contaminated soil.

The GC chromatograms of residual UEO extracted from abiotic control (Fig. 5a), MSM medium inoculated with strain HM-1 (Fig. 5b), strain HM-2 (Fig. 5c), and their mixture (Fig. 5d) exhibited total peak area of, 100,846, $56,307,75,598$, and 50,369, respectively. Thereby, the percentage of total peak area disappeared upon treatments was $44.17,25.04$, and $50.05 \%$, respectively, as compared to the control. These results confirmed the UEO biodegradation potential of these strains. Besides, the mixture was more efficient than the pure individual cultures. The TPHs were determined in instead of individual petroleum components due to the fact that used engine oil has extremely variable composition and altered structure according to the degree of combustion process during its functioning (Adesodum and Mbagwu 2008).

\section{Influence of gamma irradiation}

As pointed out in Fig. 6, gamma irradiation enhanced the biodegradation potential of bacterial mixture. The highest biodegradation level $(95 \pm 2.1 \%)$ was achieved at dose $1.5 \mathrm{kGy}$ as compared to the non-irradiated mixture $(79 \pm 1.6 \%)$. In contrast, $75,80,79,80$, and $81 \%$ were attained at $0.5,1,2,2.5$, and $3 \mathrm{kGy}$, respectively. It is speculated that the improved activity of the irradiated cells may be attributed to the changes occurred at the genetic level, i.e., a mutation in the gene(s) that encode for the enzymes involved in the biodegradation process or the enhancement in biosurfactant/bioemulsifier production which in turn increase the availability of used engine oil. Physical mutagenesis employing different irradiation methods has been adopted as one of many strategies to mutate bacteria. There are many examples concerning the potential efficiency of physical mutagenesis, such as UV and gamma irradiations to enhance the production of different biocatalysts. A gamma-ray-induced mutant of Pseudomonas aeruginosa strain S8 was isolated and designated as $P$. aeruginosa $\mathrm{EBN}-8$. This mutant revealed 3-4 times more crude oil biodegradation and emulsification when grown on Khaskheli crude oil in minimal medium as compared to the parent strain (Iqbal et al. 1995). Similarly, an improved biodegradation of crude oil in aqueous phase was achieved utilizing the mutant $D i$ etzia sp. obtained by random mutagenesis of parent $\mathrm{Di}$ etzia sp. employing ${ }^{60} \mathrm{Co}$ gamma irradiation. A genetically stable mutant, designated as M22, was isolated and approved significantly higher degradation percentage $(52.5 \%)$ of total petroleum hydrocarbons (TPHs) than the wild strain $(28.2 \%)$ in liquid media after incubation for 14 days. This enhancement was ascribed to 

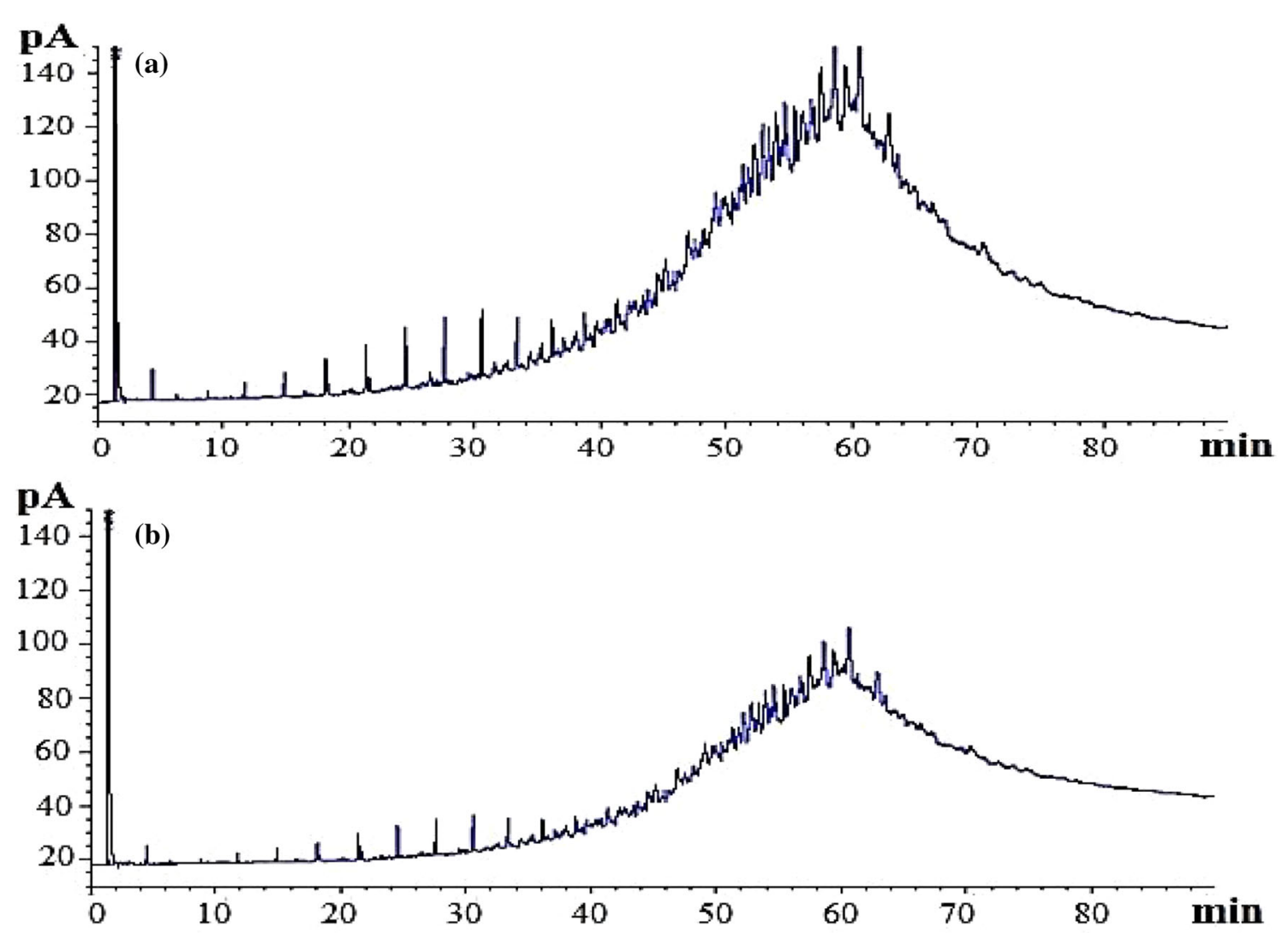

pA
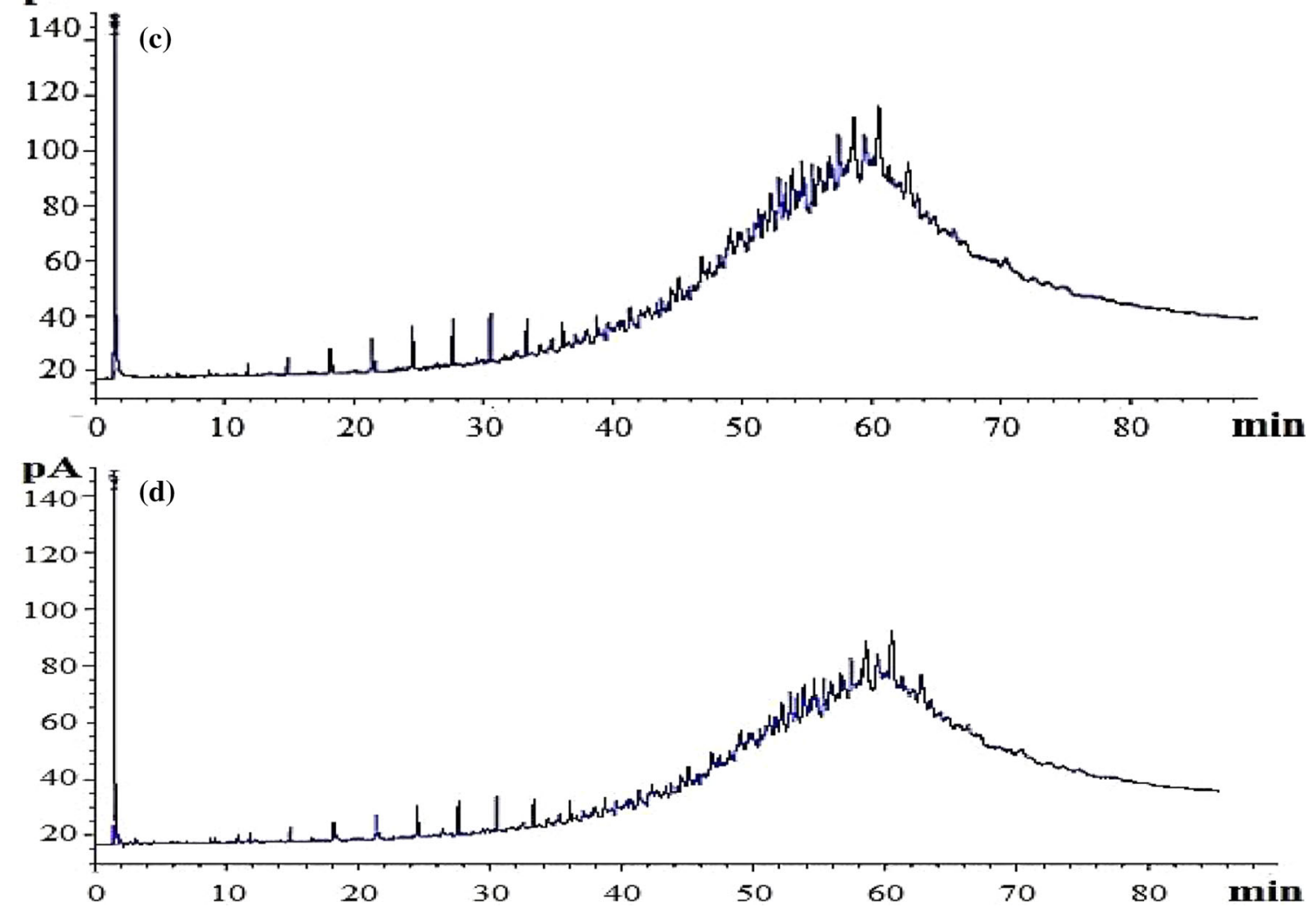

Fig. 5 GC chromatograms of residual UEO in MSM after incubation for 21 days at optimum conditions. Abiotic control (a), inoculated with strain HM-1 (b), strain HM-2 (c), and their mixture (d) 


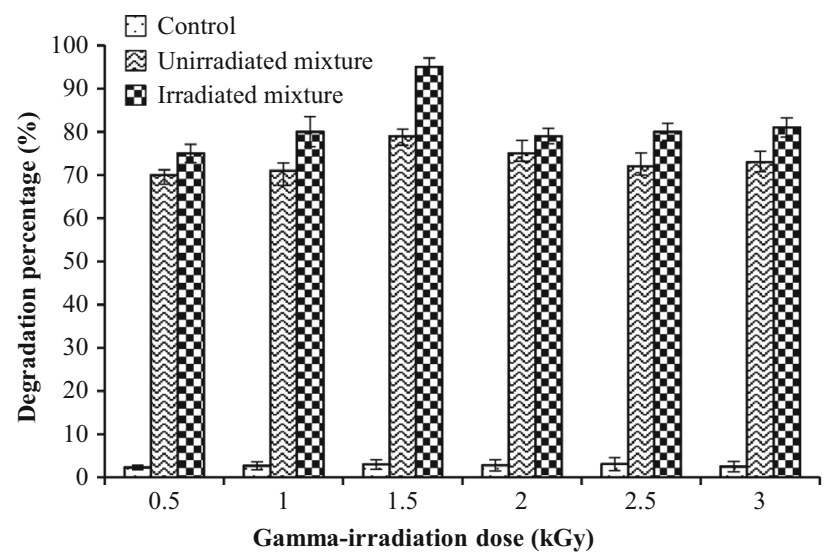

Fig. 6 Effect of gamma irradiation on the biodegradation efficiency of $O$. anthropi HM-1 and $C$. freundii HM-2 mixture under optimum conditions. Error bars represent SD values of three independent experiments $(n=3)$

increase production of enzymes responsible for the degradation by the mutant strain (Duan et al. 2015).

\section{Conclusions}

This study demonstrated the potential of native bacterial consortium encompasses $O$. anthropi $\mathrm{HM}-1$ and $C$. freundii HM-2 for bioremediation of UEO-contaminated soil. Each individual strain in the co-culture has a significant role and may be dependent on the presence of the other strain for surviving and biodegradation. The mixture demonstrated higher degradation efficiency of UEO than the individual cultures, possibly due to the synergy effect. Gamma irradiation significantly enhanced the biodegradation potential of the co-culture. Therefore, strains HM-1 and HM-2 can be employed to develop a cost-effective and eco-friendly method for the bioremediation of used engine-oil-polluted soil.

\section{Compliance with ethical standards}

Conflict of interest The author states that he has no conflict of interest.

Open Access This article is distributed under the terms of the Creative Commons Attribution 4.0 International License (http:// creativecommons.org/licenses/by/4.0/), which permits unrestricted use, distribution, and reproduction in any medium, provided you give appropriate credit to the original author(s) and the source, provide a link to the Creative Commons license, and indicate if changes were made.

\section{References}

Abioye PO, Agamuthu P, Aziz AR (2012) Biodegradation of used motor oil in soil using organic waste amendments. Biotechnol Res Int. doi:10.1155/2012/587041
Abusham RA, Rahman RN, Salleh AB, Basri M (2009) Optimization of physical factors affecting the production of thermo-stable organic solvent-tolerant protease from a newly isolated halo tolerant Bacillus subtilis strain Rand. Microb Cell Fact 8:20-28

Adelowo OO, Alagbe SO, Ayandele AA (2006) Time-dependent stability of used engine oil degradation by cultures of Pseudomonas fragi and Achromobacter aerogenes. Afr J Biotechnol 5:2476-2479

Adesodum JK, Mbagwu JSC (2008) Biodegradation of waste lubricating petroleum oil in a tropical alfisol as mediated by animal droppings. Bioresour Technol 99:5659-5665

Akio U, Mohammad H, Isao Y, Hidetoshi O (2006) Verification of degradation of $\mathrm{n}$-alkane in diesel oil by Pseudomonas aeruginosa strain WatG in soil microcosms. Curr Microbiol 52:182-185

Akoachere JFTK, Akenji TN, Yongabi FN, Nkwelang G, Ndip RN (2008) Lubricating oil-degrading bacteria in soils from filling stations and auto-mechanic workshops in Buea, Cameroon: occurrence and characteristics of isolates. Afr $\mathrm{J}$ Biotechnol 7:1700-1706

Aleer S, Adetutu EM, Makadia TH, Patil S, Ball AS (2011) Harnessing the hydrocarbon-degrading potential of contaminated soils for the bioremediation of waste engine oil. Water Air Soil Pollut 218:121-130

Bhattacharya M, Biswas D (2014) Enhancement of waste engine oil biodegradation by optimization of media using factorial design study. Indian J Biotechnol 13:293-300

Bhattacharya M, Biswas D, Santanu Sana S, Datta S (2015) Biodegradation of waste lubricants by a newly isolated Ochrobactrum sp. C1. 3 Biotech 5:807. doi:10.1007/s13205015-0282-9

Darvishi P, Ayatollahi S, Mowla D, Niazi A (2011) Biosurfactant production under extreme environmental conditions by an efficient microbial consortium, ERCPPI-2. Colloids Surf B Biointerfaces 84:292-300

Deng M-C, Li J, Liang F-R, Yi M, Xu X-M, Yuan J-P, Wu C-F, Wang J-H (2014) Isolation and characterization of a novel hydrocarbon-degrading bacterium Achromobacter sp. HZ01 from the crude oil-contaminated seawater at the Daya Bay, southern China. Mar Pollut Bull 83:79-86

Duan X-G, He Y-M, Li Z-Q, Li S (2015) Enhanced biodegradation of oily wastewater through nuclear irradiation mutation and statistical experimental methodology. J Water Reuse Desalination 5:301-311

Farahat LA, El-Gendy NS (2008) Biodegradation of Baleym mix crude oil in soil microcosm by some locally isolated Egyptian bacterial strains. Soil Sediment Contam 17:150-162

Franzetti A, Tamburini E, Banat IM (2010) Applications of biological surface active compounds in remediation technologies. Biosurfactants 672:121-134

Ghazali FM, Abdul Rahman RNZ, Salleh AB, Basri M (2004) Biodegradation of hydrocarbons in soil by microbial consortium. Int Biodeterio Biodegrad 54:61-67

Gómez MJ, Pazos F, Guijarro FJ, de Lorenzo V, Valencia A (2007) The environmental fate of organic pollutants through the global microbial metabolism. Mol Syst Biol 3:1-11

Holt SG, Kriey NR, Sneath PHA, Staley JT, Williams ST (1998) Bergey's Manual of Determinative Bacteriology. Williams and Wilkins, New York

Huang L, Ma T, Li D, Liang FL, Liu RL, Li GQ (2008) Optimization of nutrient component for diesel oil degradation by Rhodococcus erythropolis. Mar Pollut Bull 56:1714-1718

Husaini A, Roslan HA, Hii KSY, Ang CH (2008) Biodegradation of aliphatic hydrocarbon by indigenous fungi isolated from used motor oil contaminated sites. World J Microbiol Biotechnol 24:2789-2797 
Iqbal S, Khalid ZM, Malik KA (1995) Enhanced biodegradation and emulsification of crude oil and hyperproduction of biosurfactants by a gamma ray-induced mutant of Pseudomonas aeruginosa. Lett Appl Microbiol 21:176-179

Jain PK, Gupta VK, Pathak H, Lowry M, Jaroli DP (2010) Characterization of $2 \mathrm{~T}$ engine oil degrading indigenous bacteria, isolated from high altitude (Mussoorie), India. World J Microbiol Biotechnol 26:1419-1426

Jin B, van Leeuwen HJ, Patel B, Yu Q (1998) Utilisation of starch processing wastewater for production of microbial biomass protein and fungal $\alpha$-amylase by Aspergillus oryzae. Bioresour Technol 66:201-206

Kalyani KA, Pandey KK (2014) Waste to energy status in India: A short review. Renew Sustain Energy Rev 31:113-120

Koma D, Sakashita Y, Kubota K, Fujii Y, Hasumi F, Chung SY, Kubo M (2003) Degradation of car engine base oil by Rhodococcus sp. NDKK48 and Gordonia sp. NDKY76A. Biosci Biotechnol Biochem 67:1590-1593

Larik IA, Qazi MA, Kanhar AR, Mangi S, Ahmed S, Jamali MR, Kanhar NA (2016) Biodegradation of petrochemical hydrocarbons using an efficient bacterial consortium: A2457. Arab J Sci Eng 41:2077-2086

Morikawa M, Hirata Y, Imanaka TA (2000) A study on the structurefunction relationship of lipopeptide biosurfactants. Biochim Biophys Acta 1488:211-218

Obayori OS, Ilori MO, Adebusoye SA, Oyetibo GO, Amund OO (2008) Pyrene degradation potentials of Pseudomonas species isolated from polluted tropical soils. World J Microbiol Biotechnol 24:2639-2646

Salam LM (2016) Metabolism of waste engine oil by Pseudomonas species. 3 Biotech 6:98-107

Sarma A, Sarma H (2010) Enhanced biodegradation of oil products by some microbial isolate supplemented with heavy metals. Int J Bot 6:411-448

Sarubbo LA (2006) Production and stability studies of the bioemulsifier obtained from a strain of Candida glabrata UCP 1002. J Biotechnol 9:400-406

Singh A, Kuhad R, Ward O (2009) Advances in applied bioremediation. Springer, Berlin

Su WT, Wu BS, Chen WJ (2011) Characterization and biodegradation of motor oil by indigenous Pseudomonas aeruginosa and optimizing medium constituents. J Taiwan Inst Chem Eng 42:689-695

Udeani TKC, Obroh AA, Azubike N (2009) Isolation of bacteria from mechanic workshops soil environment contaminated with used engine oil. Afr J Biotechnol 8:6301-6303

Wang XB, Chi CQ, Nie Y, Tang YQ, Tan Y, Wu G, Wu XL (2011) Degradation of petroleum hydrocarbons (C6-C40) and crude oil by a novel Dietzia strain. Bioresour Technol 102:7755-7761

Wongsa P, Tanaka M, Ueno A, Hasanuzzaman M, Yumoto I, Okuyama H (2004) Isolation and characterization of novel strains of Pseudomonas aeruginosa and Serratia marcescens possessing high efficiency to degrade gasoline, kerosene, diesel oil, and lubricating oil. Curr Microbiol 49:415-422 